Japanese Psychological Reiearch

1987. Vol. 29, No.1, 1-9

\title{
Intersensory influences on the perception of apparent movement $^{1}$
}

\author{
HIDEKO OHMURA \\ Depariment of Psychology, Kytshu Instihute of Disign, Minami-ku, Ftkuoka 815
}

\begin{abstract}
Previous findings on intermodal apparent movement indicate that intersensory effect in it is asymmetric with respect to acoustic and visual systems. It has also been suggested that the difference between the latencies for the light stimulus and for the sound stimulus may coincide with the point of maximum facilitation in perception. The present study examined whether stimulation of the visual and auditory modalities acted symmetrically or reciprocally in their influence on each other under the different stimulus-onset asynchronies in apparent motion. The resalts were as follows: (1) Intersensory effect was asymmetric with respect to acoustic and visual systems, that is, only the effect of visual stimulus on auditory apparent movement was found. (2) There were two kinds in this effect: suppression in the shorter range of SOA and facilitation in the longer range. (3) The difference between the latencies for the single stimuli had no infuences on likelihood of perceived movement. These findings are discussed along the transsensory view.
\end{abstract}

Key words: intermodal apparent movement, difference between latencies for stimulus, asymmetrical effect, the transsensory view.

With respect to the psychological study of intersensory relations, greater significance and importance of the problem rose early in the 20th century. The first observations of some importance on the problem of heteromodal relations were offered by Hornbostel (1927), who identified a 'primitive intermodal function' common to all the sense organs and consisting in the capacity to perceive tones (brightness, darkness). Subsequently, it was suggested that a stimulus of one sensory modality must influence a stimulus of another sensory modality; such as the relationship between visual and acoustic sensations (Schiller, 1932a, 1932b, 1935; Zietz, 1931), a modification of visual perception by an acoustic stimulus-an 'intermodal reciprocal influence '-(Börenstein, 1936; Hilgard, 1933). Moreover, it was also pointed out that the time element, in the form of intermittency and repetition, appears to facilitate multisensory integration

This study was supported by a Grant in Aid for Scientific Researches (No. 58510059), Ministry of Education, Science and Culture of Japan, to Hideko Ohmura.
(Schiller, 1935; Zietz \& Werner, 1928). The study of apparent movement has been carried out most thoroughly in the visual modality (Aarons, 1964; Graham, 1965; Kolers, 1972; Neuhaus, 1930; Wertheimer, 1912), but the phenomenon has also been observed in the auditory (Briggs \& Perrott, 1972; Burt, 1917) and haptic (Sherrick \& Rogers, 1966) modalities as well. Hereupon, the intersensory relation among these apparent movements became a center of attention.

Allen and Kolers (1981) conducted a series of studies to determine the psychophysical characteristics of multimodal apparent movement and thereby to clarify the interactions of heteromodal stimuli involving apparent movement. The results were as follows: (1) There is not any apparent movement of a composite object-a "luminous sound" or a "sonorous light"-moving between a visual and an auditory stimulus (Zapparoli \& Reatto, 1969). (2) Simultaneous presentation of the first auditory stimulus and a visual stimulus facilitates the perception of auditory apparent movement, while simul- 
taneous presentation of the first visual stimulus and an auditory stimulus does not facilitate the perception of visual apparent movement. From these findings, they concluded that the different senses are not under the guidance of a single synthesizing or organizing system, but the perceptual system comprises independent members although capable of communicating with one another. Though they gave the view of heteromodal interaction, they insisted that intersensory influences on the perception of apparent movement are asymmetric with respect to the visual and auditory systems.

Many studies concerning other effects of auditory stimulus on visual apparent movement have already been reported. Maass (1938) tachistoscopically presented visual figures which were ambiguous with respect to the direction of perceived apparent movement. When they were accompanied by sound rhythms, there was a decrease in the variety of perceived movement. The rhythmus apparently reduced the ambiguity of the figures. Gilbert (1939) found that simultaneous auditory stimuli tended to increase the range of ISI in which visual apparent movement occurred. Hall and Earle (1952, 1954) found that the path of apparent movement between two lights appeared curved when an audible metronome made the clectrical contacts that turned on the lights.

Hilgard (1933) found, using light and sound stimuli slightly offset in time, that the magnitude of the cyeblink to sound was augmented when the light preceded the sound by intervals of 25 and $50 \mathrm{~ms}$. Thus, he maintained, there was a summation of "reaction tendencies" when the stimuli were presented at an interval equal to the differences in the latencies of their respective responses. Herschenson (1962) reported an experiment in which $\mathrm{RTs}$ were measured to light and sound presented singly and in combination. He showed the results; (1) intersensory facilitation was demonstrated in that, for cer- tain asynchronies, RTs were faster to the combination than to either stimulus alone, (2) maximum facilitation occurred at or just beyond the point at which the asynchrony was equal to the difference in $\mathrm{RT}$ to the single stimuli.

In the case of Allen and Kolers, described above, the presentation of visual and auditory stimuli was simultaneous, and the differences in their latencies were not considered. It seems that tehir failure to obtain the effect of sound on visual apparent movement is due to the fact that $\mathrm{RT}$ is faster to the sound stimulus than to the light stimulus. According to Herschenson's view (1962), the relatively fast response of the nervous system to an auditory stimulus presented simultaneously with the first of a pair of visual stimuli precedes the time interval during which heteromodal stimulation could contribute to the generator function for visual apparent movement. On the other hand, since the sensory process in apparent movement extends over a considerable period of time, the relatively slow response of nervous system to a visual stimulus presented simultaneously with the first of a pair of auditory stimuli could facilitate the perception of auditory apparent movement.

In the present study, a series of experiments was conducted to clarify the interactions of heteromodal stimuli in apparent movement. In Exp. I, reaction time to sound and light each was measured, and in Exp. II, the effects of sound (or light) on visual (or auditory) apparent movement were examined, taking the differences in their RTS in consideration.

\section{Experiment I}

\section{Method}

Stimuli. Light.-As a visual stimulus, a red light-emitting diode (luminance $220 \mathrm{~cd} / \mathrm{m}^{2}$ ) covered with a sheet of black paper, cutting a small hole (diameter 
$6 \mathrm{~mm}, 0.7^{\circ}$ ) on it, was set on a black board. A small fixation point (green light-emitting diode, luminance $6 \mathrm{~cd} / \mathrm{m}^{2}$, diameter $1 \mathrm{~mm}, 0.11^{\circ}$ ) was set at the lower part $3^{\circ}$ below it, and presented during the experiment. The distance from the position of the right eye of subjects to the plane of the stimulus presentation was $75 \mathrm{~cm}$, and their heads were fixed by a chin-rest. They observed the stimulus monocularly.

Sound.- Auditory stimuli $(500 \mathrm{~Hz}$ sine waves) were generated by a C.R. Oscillator A G-203 (TRIO) controlled by a tone burst generator, and were amplified by a Pre-Main Amplifier P.M.A-730 (Denon). These stimuli were presented via Pioneer Monitor 5 stereo headphones to the observer's right ear. Loudness was $70 \mathrm{~dB}$ as measured with a General Radio 1551-C sound level meter with a flat plate coupler.

Temporal conditions. The exposure duration of the stimuli (both light and sound) was fixed at $80 \mathrm{~ms}$. An intercycle interval (ICI) between trials was $7 \mathrm{~s}$. The exposure duration of the fixation point was $3.3 \mathrm{~s}$, and after its onset the stimulus was presented at the interval of either 2.0, 2.3 or $2.6 \mathrm{~s}$ randomly. These temporal conditions were controlled by a digital timer.

Subjects. Four students served as subjects. All had normal vision and hearing and were well acquainted with the experiment of apparent movement.

Procedure. Observation began after 10 min dark adaptation. First, the fixation point, which served also as a warning stimulus, was presented for $3.3 \mathrm{~s}$, and then the light stimulus (or the sound) was presented for $80 \mathrm{~ms}$ at intervals of either 2.0 , 2.3 or $2.6 \mathrm{~s}$ from the onset.

A block of trials consisted of 21 reactions to a particular stimulus (for example, light). Two blocks-light alone and sound alone-made up a series. Two series a day were given two times for each subject: four series (eight blocks), 168 trials in all. The sequence of the block
Table 1

Means RTs (ms) and $S D$ to light and sound stimulus for each subjects $\Delta t=\bar{L}-\bar{S}$

\begin{tabular}{lllllll} 
& \multicolumn{2}{c}{ Light } & \multicolumn{3}{c}{ Sound } \\
& RTs & $S D$ & RTs & $S D$ & $\Delta t$ \\
& & & & $\ldots$ & \\
Sub. 1 & 203 & 17 & 146 & 10 & 57 \\
Sub. 2 & 199 & 16 & 146 & 13 & 53 \\
Sub. 3 & 200 & 14 & 140 & 13 & 60 \\
Sub. 4 & 201 & 12 & 142 & 11 & 59
\end{tabular}

was changed from series to series.

Four practice trials were given before each block. A 2 min rest period was given between blocks, and a 30 min rest period between series. The subject was instructed to respond as quickly as possible to the particular stimulus perceived, and to press a key at hand with his right forefinger. Thus, the reaction times (RTs) to the stimulus were measured by the RTs measuring instrument, and were recorded by a digital printer.

The longest and shortest RTs for each block were discarded leaving 19 RTs per block. Accordingly a total of 152 RTs (76 light, 76 sound) served as data for each subject.

\section{Results}

Table 1 contains mean RTs and $S D_{\mathrm{s}}$ for the light stimulus alone and for the sound stimulus alone. The values of $\Delta t$ indicate the amount by which RT was faster to the sound stimulus than to the light stimulus. The value of difference between mean RTs (201 ms) to the light and those (144 ms) to the sound was $57 \mathrm{~ms}$. These results closely resemble those of Hilgard (1933) and Herschenson (1962).

\section{Experiment II}

It has been shown, from the results of Exp. I, that the RTs to the sound are shorter than to the light. Allen and Kolers (1981) have already demonstrated that simultaneous presentation of the first auditory stimulus and a visual stimulus 
facilitates the perception of auditory apparent motion, but simultaneous presentation of the first visual stimulus and an auditory stimulus has no effect on the perception of visual apparent movement. In this case, difference between reaction times to light and to sound were not considered at all. It was questioned, therefore, whether this fact resulted in asymmetry of intersensory influences on the perception of visual and auditory apparent movement.

In the present experiments, characteristics of the heteromodal interaction in apparent movement were examined, under the condition where the intermodal stimuli were presented at an equal interval to the differences in the latencies of their respective responses. The experiments were divided into two serics. One was the cxperiment to test the effect of sound on visual apparent movement, and the other to test the effect of light on auditory apparent mosement.

\section{Method}

Apparatus, stimuli and subjects were the same as in Exp. I.

Procedure. Visual apparent movement.Two spots of light $\left(0.7^{\circ}, 220 \mathrm{~cd} / \mathrm{m}^{2}\right)$ were successively presented on the black board under specified temporal conditions. One of these stimuli, the first stimulus, was placed to the right and another, the second, was placed to the left of the fixation point, with the separation between them of the spatial distance of $5.3^{\circ}$. A small fixation point (green light-emitting diode, diameter $0.11^{\circ}$, luminance $13.3 \mathrm{~cd} / \mathrm{m}^{2}$ ) was set on the lower part $2.5^{\circ}$ below the center between these lights. The exposure duration of each stimulus light was $80 \mathrm{~ms}$. The time interval between the onsets of these $\left(\mathrm{SOA}_{1}\right.$ : stimulus-onset asynchrony) were $90,110,130,150,180,210$ and $250 \mathrm{~ms}$, and an intercycle interval (ICI) between the offset of the second stimulus and the onset of the first was $800 \mathrm{~ms}$.

In order to examine the effect of sound on the perception of visual apparent movement, five different experimental conditions and a control condition were set, and their results were compared. With the experimental condition, a tone was presented via the stereo headphone to the subjects' right car at each of five temporal points $\left(\mathrm{SOA}_{2}\right)$ after the onset of the first visual stimulus. These $\mathrm{SOA}_{2} \mathrm{~s}$ were 0, 30, 50, 70 and $90 \mathrm{~ms}$. For example, the condition of $\mathrm{SOA}_{2} 0 \mathrm{~ms}$ indicates the simultaneous presentation of the first light and the tone, and the condition of $\mathrm{SOA}_{2}$ $50 \mathrm{~ms}$ indicates that the tone is presented $50 \mathrm{~ms}$ after the onset of the first light. The exposure duration of tone was also $80 \mathrm{~ms}$. In the control condition, two lights were presented successively under five different $\mathrm{SOA}_{1} \mathrm{~s}$.

Preceding the experiment, each subject adapted to the dark room for $10 \mathrm{~min}$. He was instructed to report if apparent movement was perceived between two lights in both the conditions. In the experimental condition 35 conditions, defined by the combinations of the five steps of $\mathrm{SOA}_{2}$ with seven kinds of $\mathrm{SOA}_{1}$, were given five times in random order. Each sulject, therefore, was exposed to a total of 175 presentations. In the control condition five trials for each of the seven steps of $\mathrm{SOA}_{1}$ were given in random order. Each subject, therefore, was exposed to a total of 35 presentations. The order of presentations of both the experimental and the control condition was counterbalanced between subjects. The stimuli (two lights) were repeatedly given until the subjects were able to report whether movement was seen or not.

Auditory apparent movement.-Two tones, as in Exp. I, were successively and dichotically presented via the stereo headphone. They heard, therefore, apparent movement between two stimuli under appropriate temporal conditions. The reason why the localization of stimuli was not presented via loudspeakers is that auditory spatial acuity is generally poor and de- 
clines markedly as the sound source deviates from the median plane (Mills, 1958; Allen \& Kolers, 1981). With headphone presentation, subjects completely lateralized the monaural stimuli to one edge or the other of intracranial space, that is, they heard a tone in one ear or the other. So, all subjects were able to obtain good apparent movement between auditory stimuli. The exposure duration of the tones was $800 \mathrm{~ms}$, and five steps of $\mathrm{SOA}_{1}$ between both tones were $10,30,50,70,90$, 120 and $150 \mathrm{~ms}$. ICI was the same as in visual apparent movement.

To test the effect of visual stimulus on the perception of auditory apparent movement, five different experimental conditions and a control condition were set. In the experimental conditions, a spot of light was presented on the black board at the distance $75 \mathrm{~cm}$ from the position of the subject's right eye, at each of five temporal points $\left(\mathrm{SOA}_{2}\right)$ by which the light preceded the first of a pair of the tone stimuli. These $\mathrm{SOA}_{2} \mathrm{~s}$ were $0,30,50,70$ and $90 \mathrm{~ms}$. In the control condition, two tones were presented successively without the light under five different $\mathrm{SOA}_{1}$ s. Both the exposure durations of the light and of the sound were $80 \mathrm{~ms}$.

Prior to testing, the subjects dark-adapted for $10 \mathrm{~min}$. Then, they reported on the perception of apparent movement between the two tones, while they maintained fixation monocularly during testing.

In the experimental conditions, 35 different conditions, specified by the combinations of the seven steps of $\mathrm{SOA}_{1}$ with the five steps of $\mathrm{SOA}_{2}$, were given five times in random order. Accordingly each subject was exposed to a total of 175 presentations. In the control condition, five trials for each of seven steps of $\mathrm{SOA}_{1}$ were given in random order. Each subject, therefore, was exposed to a total of 35 presentations. The order of presentation of both the experimental and the control condition was counterbalanced between subjects.

The testing of auditory apparent move- ment was always preceded by that of visual apparent movement. The number of occurrences of perceived movement by the four subjects made for each modality at each of the seven values of $\mathrm{SOA}_{1}$ was converted to a proportion.

\section{Results}

In Fig. 1, the likelihood of visual apparent movement, under the control and the experimental conditions, is shown as a function of $\mathrm{SOA}_{1}$. The results indicate that all the curves of perceived movement overlap closely. First, two-way $\left(\mathrm{SOA}_{1}\right.$ $\times \mathrm{SOA}_{2}$ ) analysis of variance (using a computer program "SPF 1. QR" by Shinohara, 1985) was carried out on the results of the experimental conditions, in which the first light stimulus was acconpanied by the sound. The factors were $\mathrm{SOA}_{1}$ and $\mathrm{SOA}_{2}$. The $\mathrm{SOA}_{1}$ effect was significant $(F(6,18)=36.76, p<0.01)$, but the $\mathrm{SOA}_{2}$ effect did not approach significance $(F(4,12)=2.04, p>0.05)$. The scores by these five experimental conditions were pooled for each $\mathrm{SOA}_{1}$, and these results were compared with those of the control condition. Two-way (conditions $\times \mathrm{SOA}_{1}$ ) analysis of variance was performed on these data. The results were

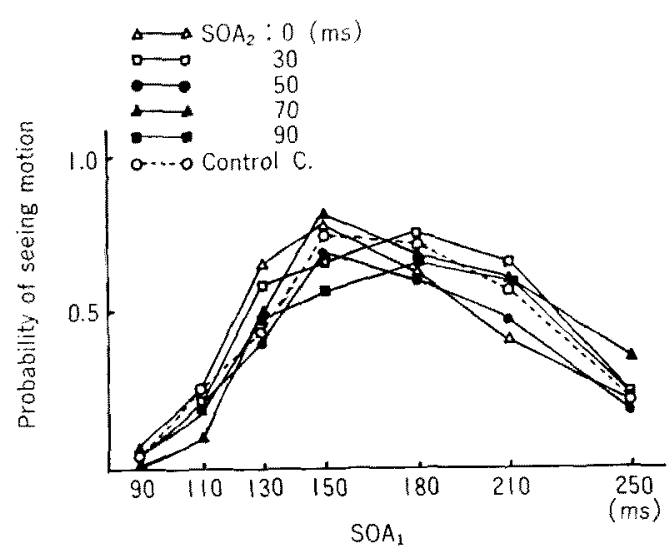

Fig. 1. Proportion report of visual apparent movement as a function of $\mathrm{SOA}_{1} \mathrm{~s}$, in five different experimental conditions (the first light stimulus with a tone stimulus) and in a control condition (visual stimulation alone). 
as follows: The $\mathrm{SOA}_{1}$ effect was significant $(F(6,18)=18.20, p<0.01)$, but the conditions effect was not $(F(1,3)=0.14$, $p>0.05)$. These results show that the sound stimulus has no effect on the occurrences of visual apparent movement, and that the differences between reaction times to the visual and the auditory stimulus do not facilitate the occurrences of visual apparent movement.

In Fig. 2, the likelihood of auditory apparent movement, under the control and the experimental conditions, is shown as a function of $\mathrm{SOA}_{1}$. The curves of auditory apparent movement, as compared with those of risual apparent movement, are similar in form, but in the latter the results of the experimental conditions are different from those of the control condition. All five curves in the experimental conditions closely resemble each other in their course. The peaks of the curves are at about $70 \mathrm{~ms} \mathrm{SOA}_{1}$, in both the experimental and the control conditions. The probabilities of perceived (auditory) movement, however, were greater in the control condition than in the experimental at the shorter range of $\mathrm{SOA}_{1}$ (below $70 \mathrm{~ms}$ ).

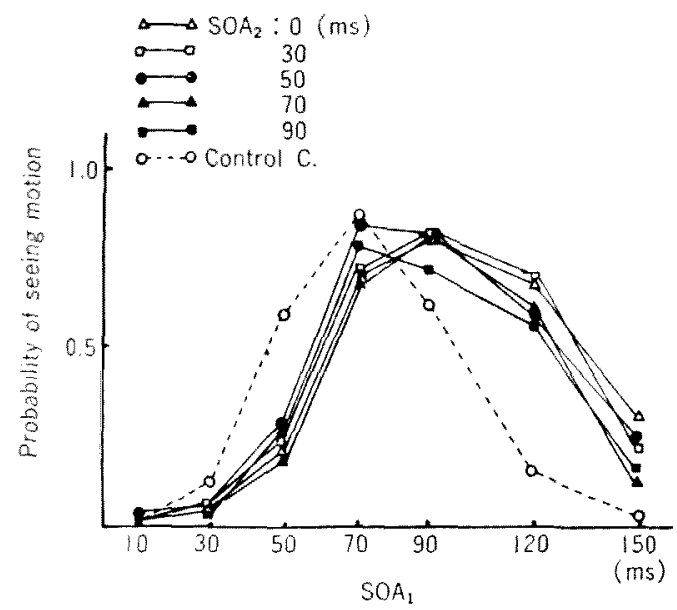

Fig. 2. Proportion report of auditory apparent movement as a function of $\mathrm{SOA}_{1} \mathrm{~s}$, in five different experimental conditions (the first tone stimulus with a light stimulus) and in a control condition (auditory stimulation alone).
On the contrary, they were greater in the experimental conditions than in control at the longer range of $\mathrm{SOA}_{1}$ (over $70 \mathrm{~ms}$ ).

Two-way $\left(\mathrm{SOA}_{1} \times \mathrm{SOA}_{2}\right)$ analysis of variance was carricd out on the data in the experimental conditions, The main effect of $\mathrm{SOA}_{\mathrm{I}}$ was significant $(F(6,18)=43.28$, $p<0.01)$, but that of $\mathrm{SOA}_{2}$ was not $(F(4$, $12)=0.98, p>0.05)$. Neither was the interaction effect between $\mathrm{SOA}_{1}$ and $\mathrm{SOA}_{2}$ significant $(F(24,72)=0.69, p>0.05)$.

Since the $\mathrm{SOA}_{2}$ effect in the experimental conditions was not significant, these scores were pooled for each $\mathrm{SOA}_{1}$. The statistical analysis was carried out on these data and those of the control condition. As a result, differences between the experimental and the control conditions were not significant $(F(1,3)=2.27, p>$ $0.05)$, but the interaction was significant $(F(6,18)=8.52, p<0.01)$. Therefore, twoway analysis of variance was carried out on the data respectively which were divided into two ranges of $\mathrm{SOA}_{1}$, the shorter and the longer than $70 \mathrm{~ms}$. Both for the shorter range and for the longer range, the conditions effect was significant $(F(1$, $3)=11.35, p<0.05 ; \quad F(1,3)=26.78, p<$ 0.05 , respectively). These findings indicate the effects of visual stimulus on acoustic apparent movement; the suppression effect in the range below $70 \mathrm{~ms}$ and the facilitation in the range over $70 \mathrm{~ms}$.

\section{Discussion}

As noted earlier, Hilgard (1933) found that the magnitude of the eyeblink to sound was augmented when the light preceded the sound by intervals of 25 and $50 \mathrm{~ms}$, and suggested that the difference between the latencies for the single stimuli may be the point of maximum facilitation. Herschenson (1962) also demonstrated intersensory facilitation for paired suprathreshold light and sound stimuli, and concluded that this effect will be manifest only when one introduces the proper amount of stimulus onset asynchrony. 
Allen and Kolers (1981), in the studies of interaction of heteromodal stimuli in apparent movement, obtained the results which suggest that intersensory effect in apparent movement is asymmetric with respect to acoustic and visual systems. In their cases, however, the differences in the latencies of respective responses to the stimuli were not considered. If it is true that the differences represent time relation leading to maximum facilitation, the facilitation should be expected when the light and sound stimuli are offset in time by an amount approximately equal to the difference between the RTs to the single stimuli. According to this view, the asymmetry of intersensory effect in the perception of apparent movement should be denied.

In the present study, it was determined whether stimulation of the visual and auditory modalities acted symmetrically or reciprocally in their influence on each other by changing $\mathrm{SOA}_{2}$ between the presentations of the visual and auditory stimuli.

To accomplish this aim, reaction time to sound and light stimuli each was measured in Exp. I. As we saw, RTs to the sound stimulus were shorter than to the light, and the difference between them was $57 \mathrm{~ms}$. The differences were close to the values by Hilgard and Herschenson. The values of RTs themselves, as compared with the cases of Hilgard and Herschenson, were larger in the present experiment. It seems to depend on the differences in stimulus properties used and other experimental situations.

In Exp. II, on the basis of the above results, the temporal conditions $\mathrm{SOA}_{2} \mathrm{~s}$ between the sound and the light stimuli were arranged, and the effects of heteromodal stimulations were examined. The results were as follows: First, the auditory stimulus presented with the visual stimulus had no influences on occurrences of perceived visual movement, and there were also no effects of the stimulus onset asyn- chrony $\left(\mathrm{SOA}_{2}\right)$ on it. These findings agree with Allen and Kolers (1981) but do not support Gilbert's result (1939) that the simultaneous presentation of an acoustic and a visual stimulus increases interstimulus interval to produce visual apparent movement. Second, the visual stimulus presented with the acoustic stimulus had influences on occurrences of perceived auditory movement. But the $\mathrm{SOA}_{2}$, as in the visual apparent movement above, did not have effects on the perception of auditory apparcnt movement. This indicates that the differences in the latencies of their respective responses do not increase the intersensory effects. It was found, moreover, that there were two kinds of the effects of visual stimulus on auditory apparent movement: suppression and facilitation. These depended on the range of $\mathrm{SOA}_{1}$ s between two sound stimuli. In the range shorter than $70 \mathrm{~ms} \mathrm{SOA}_{1} \mathrm{~s}$ perceived acoustic movement with a visual stimulus was suppressed more than without it, and in the range longer than $70 \mathrm{~ms} \mathrm{SOA}_{1} \mathrm{~s}$ it was facilitated. In the case of Allen and Kolers, only the facilitation effects by the visual stimulus were found in auditory apparent movement. Since the temporal conditions of $\mathrm{SOA}_{1} \mathrm{~s}$ in their study were limited to the range of those more than $90 \mathrm{~ms}$, the suppression effects might not be found. Allen and Kolers (1981) interpreted the facilitation effects as the reinforcement or the contribution of the visual stimulus to the sensory process underlying auditory apparent motion.

If so, how are the suppression effects in the present study to be explained? In this case, the effects were found within the limits of the range shorter than $70 \mathrm{~ms}$ $\mathrm{SOA}_{1}$. Because the exposure duration of the tone stimuli was $80 \mathrm{~ms}$, there were the temporal overlaps between the perceptual responses to the successive stimuli: for example, 10, 30 and $50 \mathrm{~ms}$ for 70,50 and $30 \mathrm{~ms}$ of $\mathrm{SOA}_{1}$ respectively. On the other hand, the conditions of $\mathrm{SOA}_{2}$ in this ex- 
periment were arranged over the range of $0-90 \mathrm{~ms}$, in order to make overlap in time the perceptual responses to the first tone stimulus and to the light stimulus. The perceptual responses, therefore, to the successive tone stimuli and to the light stimulus were still more overlapped temporally. It is also generally said that the optimal SOA to obtain smooth auditory apparent motion is about $80 \mathrm{~ms}$, and so the range shorter than $70 \mathrm{~ms} \mathrm{SOA}_{1}$ in this experiment is not the condition sufficient to establish it. As the results, the visual stmulation might act to suppress the perception of apparent movement between the two tones stimulated overlapping temporally. Is already mentioned, interactions between the single stimuli in heteromodality have been clarified (Hilgard, 1933; Herschenson, 1962). No one has found evidences, however, how a single stimulus in one modality can influence the perception of two successive stimuli in the other modality, under the conditions where the perceptual responses to all the stimuli overlap temporally. The present study did not also permit to pursue this problem further.

Concerning the interrelation between different modalities, two separate possibilities might be suggested. In one, which is called suprasensory, the coordination of the separate contributions of the senses to a common perceptual experience is carried out by a mechanism external or supraordinate to the senses themselves; a common sensory mechanism which mediates the phenomenon in all modalities (Sherrick \& Rogers, 1966). In the other, which is called transsensory, the coordination is lodged within the modalities themselves: The amount and kind of visual input would be controlled by the visual system, and those of auditory input by the auditory system. Where the intersensory mechanism - a link between different senses that merely allows the activity of one to influence the activity of anotherallows only for quantitative modification of perception; a transsensory mechanism would allow for qualitative variation as well.

In the present study, the asymmetry of the interrelation between both visual and acoustic modalities seems to maintain the transsensory view. According to the suprasensory, in which a common sensory mechanism is speculated and information is directly compared, it is impossible to consider that intersensory influences on the perception of apparent motion are asymmetric with respect to the visual and auditory systems. On the contrary, it may be possible by considering the asymmetry in intersensory mechanism: It operates from the visual system to the auditory, but does not from the auditory to the visual or only weakly. The findings of this study support the Allen and Kolers' proposition that the perceptual system can be viewed as comprising independent members, although capable of communicating with one another, which strongly rejects a common sensorium.

Moreover, it seems that this asymmetry of the intersensory influences shows the predominance of vision to hearing. The perception of visual apparent movement is more stable, as compared with those in other modalities, so it is hard to be modified and changed by information of other modalities. Some evidence about the relation of visual predominance has already been offered (Rock \& Harris, 1967; Allen \& Kolers, 1981).

Hilgard (1933) and Herschenson (1962) clearly demonstrated intersensory facilitation for paired suprathreshold light and sound stimuli. It was evident that this effect is manifest only when one gives the stimuli a chance, i.e., introduces the proper amount of stimulus onset asynchrony. They suggested that the difference between the latencies for the single stimuli may be the point of maximum facilitation. On the contrary, in the present study, the perception of apparent movement is not facilitated even when the light and sound 
stimulations are offset in time by an amount approximately equal to the difference between the RTs to the single stimuli. This fact indicates that intersensory relation in the perception of simple stimulus may be different from that in apparent movement, perhaps in the level of processing of these cases.

\section{References}

Aarons, L. 196t Visual apparent movement research: Review 1935-1955 and bibliography 1955-1963. Percephal and Motor Skill, 18, 239 274.

Alen, P. G., \& Kolers, P.A. 1981 Sensory specific of apparent motion. Journal of Experimental Psychology: Human Perceplion and Performance, 7, 1318-1326.

Briggs, R. M., \& Perrott, D. R. 1972 Auditory apparent motion under dichotic listening conditions. Joumal of Experimental Psychology, 92, 8391 .

Burt, H. E. 1917 Suditory illusions of movement-A preliminary study. Joumal of Experimental Psychology, 2, 63-75.

Börenstein, W. 1936 On the functional rolations of the sense organs to one another and to the organism as a whole. Journal of Gonelic Psycholog $y, 15,117-131$.

Gilbert, G. M. 1939 Dynamic Psycho-physics and the phi phenomenon. Irchizes of Psychology, 33S (No. 237).

Graham, G. H. 1965 Vision and visual perceplion. New York: John Wiley.

Hall, K.R.L., \& Earle, A. E. 1952 A pendulum phenomenon in the visual perception of apparent movement. Quarterly Joumal of Experimental Psychology, 4, 109-120.

Hall, K.R.L., \& Earle, A.E. 1954 A further study of the pendulum phenomenon. Quarterly Journal of Experimental Psychology, 6, 112-124.

Herschenson, M. 1962 Reaction time as a measure of intersensory facilitation. Journal of $E x$ perimental Psychology, 63, 289-293.

Hilgard, E. R. 1933 Reinforcement and inhibi- tion of eyelid rellexes, Journal of General Psychology, 61, 161-265.

Hornbostel, E. M. von 1927 The unity of the senses, Psyche, 7 (4), 83-89.

Kolers, P. 1972 Aspects of motion perception. Now York: Pergamon Press.

Maass, H. 1938 Uber den Einfluss $A$ kustischer Rhylhmen aul Optische Bewegunfsgestaltungen. .trchiv für die gesammie Psychologie, 100, 424-464.

Mills, A.W. 1958 On the minimum audible angle. Journal of Acoustical Society of America, 30, 237-246.

Neuhaus, W. 1930 Experimentelle Untersuchungen der Scheinbewegung. Archiv fïr die gesamle Psychologie, 75, 315-458.

Rock, I., \& Harris, C. S. 1967 Vision and touch. Scientific America, 216, 96-101.

Schiller, P. 1932a Das optische Verschmertzen in seiner Abhängigkeit von heteromodaler Reizung. Nilschrifl für Psychologie, 125, 249-288.

Schiller, P. 1932b Die Rauhigkeit als intermodale Erscheinung. Zeilschrift für Psychologie, 127, $265-289$.

Schiller, P. 1935 Interrelation of different senses in perception. British Journal of Psychology, 25, $465-469$.

Sherrick, C.E., \& Rogers, R. 1960 Apparent haptic movement. Perception \& Psychophysics, 1, 175-180.

Shinohara, H. 1985 The basic for the behavioral science. Vol. 3. Experimenial design 2. Tokyo: Nakanishiya Press.

Wertheimer, M. 1912 Experimentclle Untersuchungen der Scheinbewegung. Archiv für die gesamte Psychologie, 75, 315-458.

Zapparoli, G. C., \& Reatto, L. L. 1969 The apparent movement between visual and acoustic stimulus and the problem of intermodal relations. Acta Psychologica, 29, 256-267.

Zietz, K., \& Werner, H. 1928 Über die dynamische Struktur der Bewegung. Zeitschrift für Psychologie, 105, 226-249.

Zietz, K. 1931 Gegenseitige Beeinflussung von Farb- und Tonerlebnissen. Zeitschrift für Psychologie, 121, 257-356.

(Received August 1, 1985; accepted Sept. 20, 1986) 